\title{
Aminoglycoside Screening Method
}

National Cancer Institute

\section{Source}

National Cancer Institute. Aminoglycoside Screening Method. NCI Thesaurus. Code C85556.

A method to determine microbial susceptibility to high concentrations of aminoglycoside antibiotics. 